\title{
The reduced urinary output after spinal cord injury: a review
}

\author{
JR Silver, JR Doggart and RG Burr \\ National Spinal Injuries Centre, Stoke Mandeville Hospital, Aylesbury, Buckinghamshire, HP21 8AL, UK
}

\begin{abstract}
Oliguria in patients following spinal cord injury was first mentioned in 1649 , but has since been referred to only occasionally. The work detailed here was completed 30 years ago but is reported because of the lack of any comparable study and because suitable patients are not now readily available. A total of 27 water load tests were carried out on 20 patients. The test included measurement of serum osmolality to confirm absorption of ingested water. Impaired response to the water load was obtained in 17 tests: $12 / 13$ between 1 and 5 days after onset of the cord lesion and 5/14 more than 2 weeks after injury. The possibilities that oliguria was due to dehydration, failure to absorb ingested water, hypotension or renal failure are discounted. In the first few days after injury, oliguria may be due to release of antidiuretic hormone as part of the metabolic response to trauma. The impaired response seen later is discussed in relation to possible neural and hormonal mechanisms. There is a need for further study of factors influencing water excretion in tetraplegic and paraplegic patients.
\end{abstract}

Keywords: spinal cord injury; oliguria; paraplegia; tetraplegia

\section{Introduction}

Diminished output of urine following acute spinal cord transection was first mentioned in 1649, when Parey described suppression of the passage of urine following spinal cord section; he attributed this to loss of sensation of the bladder causing retention of urine. ${ }^{1}$ The next mention was in 1915 when Gordon Holmes gave the Goulstonian Lectures on spinal injuries of warfare. ${ }^{2} \mathrm{He}$ was serving in France at a base hospital and saw the patients immediately after injury. Under 'description of special symptoms found in soldiers with acute cervical cord transections' he described the small amounts of urine passed: 'The fourth special symptom was the small amount of urine passed. In one man who lived $48 \mathrm{~h}$ no urine was secreted; another secreted only $20 \mathrm{oz}$ in 3 days; a third probably only $8 \mathrm{oz}$ in 4 days; while from a fourth (Figure 3) whose temperature varied between $87^{\circ} \mathrm{F}$ and $105^{\circ} \mathrm{F}$ and his pulse rate between 40 and 104, only 20 to $25 \mathrm{oz}$ could be drawn off during the first 3 days, but the daily amount increased to 50 to $60 \mathrm{oz}$ for the last 2 days, when his temperature ranged between $100^{\circ} \mathrm{F}$ and $105^{\circ} \mathrm{F}$. The amount of urea was estimated in two cases in which very little urine was secreted and its percentage was approximately normal'.

He was so interested in this symptom that he requested Professor Harvey Cushing who was serving in France at that time to see one of the soldiers. Harvey Cushing suggested the explanation was: 'a

Correspondence: Dr JR Silver, 8 High Street, Wendover, Bucks. HP22 6EA, UK cervical sympathetic palsy may disturb the functions of the pituitary and that this may interfere with the correlated activity of the suprarenals.'

Classic studies were carried out by Head and Riddoch $^{3}$ during the first world war. These were made on soldiers after they arrived in England and were at a considerable interval after the injury. They made no observations on the secretion of urine, no doubt because of the delay in the patients arriving in England.

Sir Ludwig Guttmann, because of his practice of intermittent catheterisation and his advocacy of the early transfer of the patients to the spinal unit, became interested in the phenomenon of the diminished secretion of urine immediately after a spinal cord transection.

In $1953^{4}$ he stated 'as a rule the paralysed bladder is never so distended after an acute spinal lesion as to warrant immediate drainage by any method'. He did not describe the suppression of urine at that time.

In $1966^{5}$ when he described with Frankel the method of intermittent catheterisation, he stated 'Most patients did not need catheterisation during the first $24 \mathrm{~h}$ after injury. After this period they were catheterised 2 or 3 times a day according to their urinary output, until they started to pass urine either voluntarily, automatically or by manual and abdominal expression. Most patients, especially the cervical patients, had an initial period of water retention with oliguria during the first few days after injury and during this time needed only twice-daily catheterisation; at about the 4th to 6th day or soon after there 
was often a profound diuresis and 3 or 4 litres of urine were often secreted in $24 \mathrm{~h}$. During such diuresis we temporarily reduced the fluid intake and catheterised the patients 4 or more times a day'.

In $1973^{6}$ he repeated the foregoing statement but also drew attention to the fact that the fluid balance was disturbed: 'in the early days following a transection of the cervical cord the renal function is slowed down resulting in oliguria and sometimes even anuria'.

Cheshire in $1966^{7}$ described, in patients with acute cervical injuries, avid fluid retention 'causing pulmonary oedema, peripheral oedema, sodium overloading (particularly as after the injury the patient is likely to have a positive sodium balance due to enhanced mineralo-corticoid activity) and chloride overloading with a consequent stress on the body's buffer systems'.

Lloyd et $a l^{8}$ performed water load tests on 50 patients with spinal cord dysfunction of more than 6 months duration and reported abnormal findings in 16 $(32 \%)$, defined as less than two-thirds of the fluid load returned through the kidney in $4 \mathrm{~h}$.

There has since been scant mention of this subject apart from Krishnan and Parsons ${ }^{9}$ who described changes in urinary output in an unpredictable manner following spinal injury.

The cause of this oliguria has not been determined. Suggested mechanisms have included pituitary dysfunction, surgical shock, renal impairment, mineralocorticoid activity, fluid pooling in the bowel and sympathetic dysfunction.

The subject is of considerable practical importance in view of the danger of fluid overload in the acute stage after traumatic spinal cord injury.

The water load tests reported here were carried out many years ago, many of them within $24 \mathrm{~h}$ of injury, and are published because of the lack of any similar report in the literature and because such subjects are not readily available for study in specialist centres at the present time since patients are admitted to intensive therapy units in the receiving hospital and screening for MRSA infection delays transfer.

\section{Patients}

The patients were studied between 1957 and 1964 . There were 17 males and 3 females with spinal cord injury aged 14-56 (median 28) years. They comprised 11 tetraplegic, seven having neurologically complete cord lesions and four being incomplete, and nine paraplegic patients, of whom seven were complete and two incomplete. The injuries were caused by: falls (6), diving (5), road traffic accidents (3), a blow (3), horse riding (2) and hand grenade explosion (1).

The patients were divided into three groups based on the interval that had elapsed following injury. These were: Group 1, 1-5 days (Acute: immediate post-injury period, the time when the changes had been observed), 13 tests; Group 2, 2-8 weeks (Post acute: still bedfast, to monitor progress back to normality), 6 tests; Group 3, from 5 months on (Late: rehabilitation or readmission, when the patients were expected to be normal), 8 tests. The tests in Group 2 were all repeat studies on patients previously studied in Group 1. One patient in Group 3 had previously been studied in Groups 1 and 2; the remainder were studied for the first time.

All patients were in a stable condition. None were receiving intravenous fluids or medication known to influence antidiuretic hormone (ADH) secretion. Urine test for proteinuria was negative. Two of the patients studied in Group 1 (acute) had associated injuries of some significance: one had a fractured skull, the other fractured ribs and haemothorax. The remainder had no injuries apart from that to the spine. Four of the patients studied in Group 3 (late) had remained in hospital since their first admission. The other four had been readmitted, two for pressure sores and two for investigation for renal function. Every patient admitted to the Centre was considered for the study. Many, however, were too ill, were unable to drink a litre of water and were excluded.

\section{Methods}

For the water load test, the patients were kept in bed and had a urinary catheter in situ. No fluids were allowed after midnight, the test being commenced at 9 am. Smoking was not permitted. The urinal bag was emptied and 1 litre water drunk. Urine and venous blood samples were taken initially and then at $30 \mathrm{~min}$ intervals for $3 \mathrm{~h}$. The volume of urine and either its specific gravity (SG) or osmolality were measured. Plasma and urine osmolality were determined by freezing point depression (Advanced Osmometer), urine SG by float urinometer. Reference range for serum osmolality was 285-295 mOsm l$~^{-1}$. Blood pressure and blood urea and haemoglobin were measured routinely for clinical management. One of the authors performed the test and remained with the patient throughout. A total of 27 tests were carried out.

A normal result was that of de Wardener, ${ }^{10}$ viz. excretion within $3 \mathrm{~h}$ of at least $75 \%$ of the volume ingested. Statistical tests used were: linear regression, to test for correlation between volume of urine excreted and other variables; and the KruskalWallace test, to test for a trend in urine volume from Group 1 to Group 3.

\section{Results}

Figure 1 shows a normal response. Following ingestion of 1 litre of water there was a fall in serum osmolality. About half an hour later there was a rise in the volume of urine excreted followed by a return of serum 
osmolality towards the initial value. A total of $975 \mathrm{ml}$ urine was returned in $3 \mathrm{~h}$.

Figure 2 shows an abnormal response. Serum osmolality fell but there was no increase in the volume of urine excreted.

Figure 3 shows the results in the patient studied serially.

Systolic and diastolic blood pressures at the time of the study were in the ranges $80-150$ (mean 117) and 50-110 (mean 78) $\mathrm{mm} \mathrm{Hg}$ respectively. Blood urea was $3.0-9.3$ (mean 5.8) $\mathrm{mmol} \mathrm{l}^{-1}$, and blood haemoglobin was 11.2-15.4 (mean 13.0) $\mathrm{g} \mathrm{dl}^{-1}$. There was no relationship between blood pressure, blood urea or haemoglobin and the volume of urine excreted.

In all patients the serum osmolality decreased in response to the water load. Serum osmolality at the start of the test was $272-298$ (mean 289) OOsm 1 $^{-1}$. Lowest serum osmolality during the test was $259-294$ (mean 280) mOsm l$^{-1}$, a decrease of 3-14 (mean 8) mOsm $1^{-1}$. The patients in Group 1 who gave an impaired response showed a small decrease in urine SG. In all the other tests there was a large decrease in SG or osmolality of the urine.

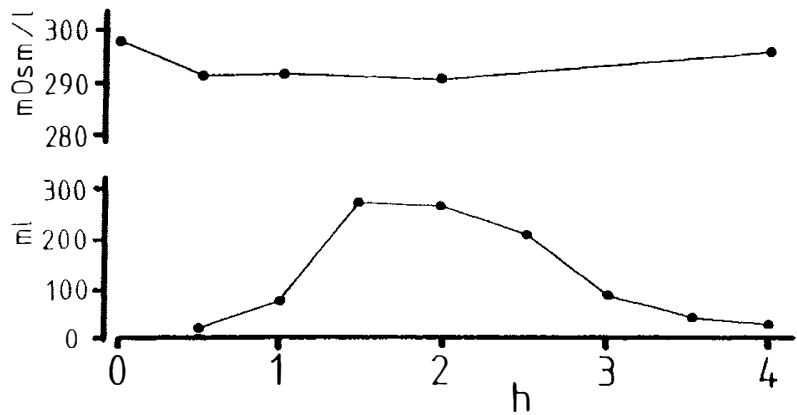

Figure 1 Example of a normal water-load test. Serum osmolalities and volume of urine excreted following the ingestion of 1 litre of water by a paraplegic patient 2 years after spinal cord injury

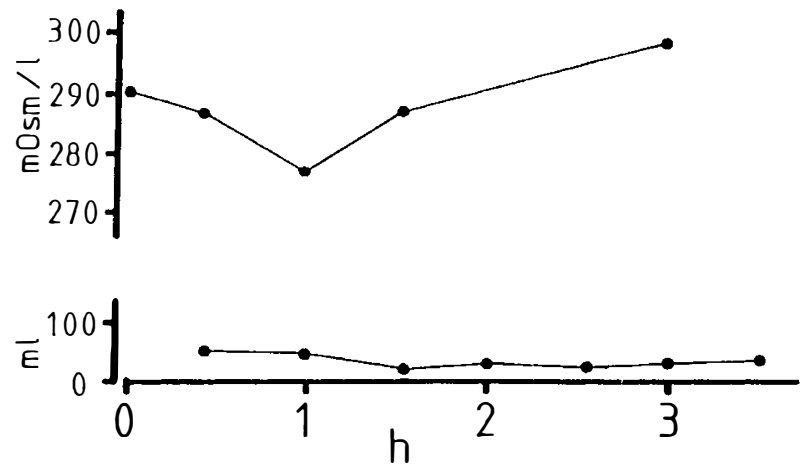

Figure 2 Example of an abnormal water-load test. Serum osmolalities and volumes of water excreted following ingestion of 1 litre of water by a paraplegic patient 5 days after spinal cord injury
Table 1 and Figure 4 show the results of all the water load tests. The result was abnormal in $17(63 \%)$. Normal responses were given by $1 / 13$ in Group 1 , by $2 / 6$ in Group 2 and by $7 / 8$ in Group 3. This trend was statistically significant $(P=0.0053)$. The response was not significantly related to the level of the cord lesion.

\section{Discussion}

At the time when these tests were carried out no bedweighing machine was available and it was not possible to give a weight-related water load. A standard load of 1 litre was therefore given.

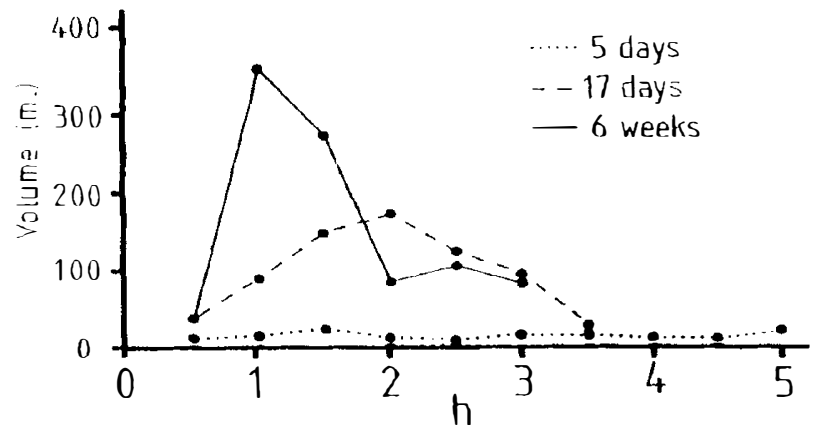

Figure 3 Results of serial study in a tetraplegic patient. Volumes of urine excreted following ingestion of 1 litre of water 5 days, 17 days and 6 weeks after spinal cord injury

Table 1 Results of the water load test

\begin{tabular}{|c|c|c|c|c|c|}
\hline $\begin{array}{l}\text { Cord } \\
\text { lesion }\end{array}$ & Gender & Age & $\begin{array}{l}\text { Group } 1 \\
1-5 \text { days }\end{array}$ & $\begin{array}{c}\text { Group } 2 \\
2-8 \text { weeks }\end{array}$ & $\begin{array}{c}\text { Group } 3 \\
>5 \text { months }\end{array}$ \\
\hline C6 & M & 52 & 69 & 645 & 913 \\
\hline T8 & M & 28 & 100 & 1063 & \\
\hline $\mathrm{T} 10 \mathrm{C}$ & M & 38 & 127 & 600 & \\
\hline $\mathrm{Ll}$ & M & 49 & 224 & 975 & \\
\hline C5 & M & 28 & 291 & 555 & \\
\hline $\mathrm{C} 4 \mathrm{c}$ & M & 14 & 345 & 460 & \\
\hline C6 & M & 56 & 130 & & \\
\hline C7 c & M & 21 & 145 & & \\
\hline C6 & M & 24 & 190 & & \\
\hline $\mathrm{T} 11 \mathrm{C}$ & M & 31 & 245 & & \\
\hline C6 & $\mathrm{F}$ & 21 & 245 & & \\
\hline $\mathrm{C} 8 \mathrm{c}$ & M & 18 & 530 & & \\
\hline $\mathrm{T} 1$ & M & 22 & 1065 & & \\
\hline $\mathrm{T} 7 \mathrm{c}$ & $\mathrm{F}$ & 28 & & & 588 \\
\hline C5 i & $\mathrm{M}$ & 16 & & & 765 \\
\hline T6 c & M & 32 & & & 836 \\
\hline C6 i & M & 22 & & & 885 \\
\hline T5 c & M & 33 & & & 918 \\
\hline T12 i & $\mathrm{F}$ & 20 & & & 959 \\
\hline $\mathrm{C} 4 \mathrm{c}$ & M & 20 & & & 1005 \\
\hline
\end{tabular}

Volumes $(\mathrm{ml})$ of urine excreted within $3 \mathrm{~h}$ following the ingestion of 1 litre of water. A normal result is $750 \mathrm{ml}$ or more 


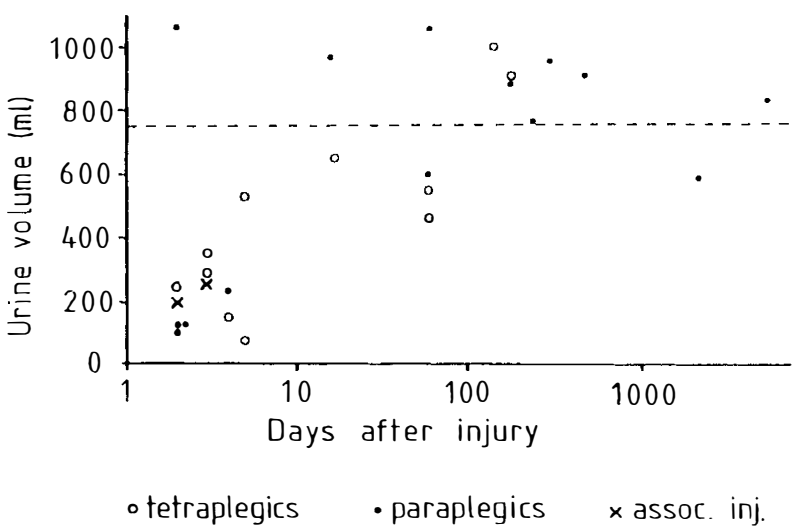

Figure 4 Results of the water-load tests. Volumes of water excreted in $3 \mathrm{~h}$ following ingestion of 1 litre of water in relation to the number of days that had elapsed after injury to the spinal cord in complete tetraplegics, in paraplegic patients with associated fractures, and in paraplegic and incomplete tetraplegic patients without associated fractures. Points above the broken line indicate a normal result

The fall in serum osmolality following ingestion of water indicated that the water was absorbed and that paralytic ileus was not present. The patients in Group 1 were selected in that they were capable of drinking a litre of water. Initial osmolality was close to the normal range indicating that the patients were well hydrated. No patient was in renal failure, as indicated by the level of blood urea at the time of the test as well as the fact that no patient subsequently developed an elevated blood urea. The lack of correlation between blood pressure and urine volume as well as the levels of blood pressure recorded suggested that blood pressure was sufficient to ensure adequate renal perfusion. Creatinine clearance in acute spinal patients is invariably normal or raised ${ }^{11}$.

Our incidence of impaired water excretion of $36 \%$ in patients two or more weeks after spinal cord injury is close to the $32 \%$ reported by Lloyd in patients 6 or more weeks after injury ${ }^{8}$. In other types of patient diminished urine production after injury is well recognised $^{12}$. Following surgery secretion of ADH rises rapidly, reaches a plateau in $6-12 \mathrm{~h}$ and declines to normal values by the 5th postoperative day in major cases. ${ }^{13}$

Oliguria associated with surgery lasts no more than 2-4 days. Some of our patients showed impaired ability to excrete a water load up to 8 weeks and, in one case, up to 6 years after spinal injury. Some other mechanism must therefore be sought.

$\mathrm{ADH}$ secretion is regulated by osmoreceptors located in the anterior hypothalamus, by low pressure receptors of the great veins, right and left atria and pulmonary vessels and by high pressure receptors situated in the carotid sinuses and the aortic arch. $\mathrm{ADH}$ secretion is increased by increased plasma osmolality, reduced extracellular fluid volume, pain, emotions such as fear or anger, surgical stress, nausea and the administration of certain drugs. ${ }^{14}$

Following a spinal cord injury an appreciable amount of blood (1-1.5 litres) is lost to the fracture site in the spine. There is also loss of the muscle pump due to paralysis of the muscles of the lower limbs. Acute blood loss is first detected by baroreceptors in the carotid artery and aortic arch as well as mechanoreceptors in the right atrium. In paraplegics compensation will occur by activation of the sympathetic nervous system. Direct effects include increased cardiac contractility and rate. Indirect effects are mediated by several powerful vasoconstrictors, which increase cardiac afterload via peripheral and splanchnic vasoconstriction in an attempt to maintain blood pressure. Increased sympathetic tone also produces vasoconstriction, which enhances cardiac preload. Considering that approximately $50 \%$ of the total blood volume is in venous capacitance vessels, this indirect effect is an important means by which preload is maintained.

It is more difficult to explain why no difference was found in this study between paraplegic and tetraplegic patients. Tetraplegic patients have lost the ability to vasoconstrict owing to compromised control of the sympathetic nervous system. Resting levels of ADH in chronic tetraplegic patients are normal, but in response to head-up tilt there is a four-fold increase in release of $\mathrm{ADH}$, in contrast to normal subjects who show no increase. ${ }^{15}$ Diurnal variation is reduced. ${ }^{16}$ In addition, tetraplegics have increased sensitivity to the effects of the hormone. ${ }^{17}$ There is decreased output of urine on the day after head-up tilt, presumably as a result of increased release of $\mathrm{ADH}$ on the previous day. ${ }^{18}$ Sepsis in tetraplegic patients is also associated with defective control of water balance. ${ }^{19}$

In the only previous report of water loading tests in patients with spinal cord injuries studies were done 6 months or more after onset. ${ }^{8}$ ADH secretion and oliguria have been well studied following surgery in patients with intact spinal cords. There have also been detailed studies of hormonal control of blood pressure and sodium and water excretion in chronic tetraplegic and paraplegic patients. The hormonal and metabolic effects of trauma in the presence of a severed spinal cord warrant further study.

Fluid retention following trauma is well recognised; it is not due to acute renal failure and attempts to produce diuresis by administering fluids and diuretics are hazardous. It is also recognised that chronic tetraplegics do not possess high tolerance to fluid loads. The mechanisms of this have been investigated. ${ }^{15-17}$ Our results indicate that abnormal fluid handling can be present in paraplegic patients as well at a considerable interval after injury. Therefore caution is required in administering fluids to all groups of spinal injured patients especially in the acute stage when fluid retention is particularly marked. 


\section{References}

1 Parey, A. The works of Ambrose Parey. Richard Coles, London. 1649, 17: 435-436

2 Holmes G. Spinal injuries of Warfare. 2. The clinical symptoms of gunshot injuries of the spine. Br Med J 1915; 815-821.

3 Head H, Riddock G. Brain 1917; 40: $188-263$.

4 Guttmann L. History of the Second World War. Surgery. 1953. Ed. Zachary Cope, London. HMSO. p 463.

5 Guttmann L, Frankel HL. Paraplegia. The value of intermittent catheterisation in the early management of traumatic paraplegia and tetraplegia. 1966; 4: $63-84$ :

6 Guttmann L. Spinal Cord Injuries - Comprehensive Management and research. Blackwell Scientific publications, Oxford. 1973; p 194

7 Cheshire DJE, Coats DA. Paraplegia. Respiratory and metabolic management in acute tetraplegia. 1966; 4: 1-23.

8 Lloyd KE, Kaplan LI, Kupperman HS, Grynbaum BB, Rusk HA. A follow-up study of patients with spinal cord dysfunction: endocrine and metabolic findings. Arch Phys Med Rehab 1964; 45: $184-192$.

9 Krishnan KR, Parsons KF. Handbook of Clinical Neurology. Elsevier, Amsterdam. 1992; 61: 301.

10 de Wardener HE. The Kidney. An outline of normal and abnormal function. Churchill Livingstone, Edinburgh. 5th Ed. 1985; p 70.
11 Doggart JR, Guttmann L, Silver JR. Comparative studies on endogenous creatinine and urea clearances in paraplegics and tetraplegics. Paraplegia 1966; 3: $229-242$.

12 Bernard C. Lecons sur les Proprietes Physiologiques des Liquides de l'Organisme. Bailliere, Paris. 1859; $172-173$.

13 Moran WH, Miltenberger FW, Shuayb WA, Zimmermann B The relationship of antidiuretic hormone secretion to surgical stress. Surgery 1964, 56: 9: $99-108$

14 Ganong WF. Review of Medical Physiology, 16th Edition, Prentice Hall, London, 1993.

15 Sved AF, McDowell FH, Blessing WW. Release of antidiuretic hormone in quadriplegic subjects in response to head-up tilt Neurology 1985; 35: $78-83$.

16 Szollar S, North J, Chung J. Antidiuretic hormone levels and polyuria in spinal cord injury. A preliminary report. Paraplegia 1995; 33: $94-97$.

17 Poole CJM, Williams TDM, Lightman SL, Frankel HL. Neuroendocrine control of vasopressin secretion and its effect on blood pressure in subjects with spinal cord transection. Brain 1987; 110: $727-735$.

18 Vallbona C, Lipscomb HS, Carter RE. Endocrine responses to orthostatic hypotension in quadriplegia. Archives of Physical Medicine and Rehabilitation. 1966; 47: 412-421.

19 Soni BM, Vaidyanthan S, Watt JWH, Krishnan KR. A retrospective study of hyponatremia in tetraplegic/paraplegic patients with a review of the literature. Paraplegia 1994; 32: 597-608. 